\title{
Preliminary biocompatible evaluation of nano-hydroxyapatite/polyamide 66 composite porous membrane
}

This article was published in the following Dove Press journal:

International Journal of Nanomedicine

19 June 2010

Number of times this article has been viewed

\author{
Yili $Q u^{1,3}$ \\ Ping Wangl,3 \\ Yi Man' \\ Yubao $\mathrm{Li}^{2}$ \\ Yi Zuo ${ }^{2}$ \\ Jidong $\mathrm{Li}^{2}$
}

'State Key Laboratory of Oral Diseases, Sichuan University, Chengdu 6I0064, China; ${ }^{2}$ Research Center for Nano-Biomaterials, Analytical and Testing Center, Sichuan University, Chengdu 610064, China; ${ }^{3}$ These authors contributed equally to this work
Correspondence: Jidong $\mathrm{Li}$ Research Center for Nano-Biomaterials, Analytical and Testing Center, Sichuan University, Chengdu 610064, PR China

Tel +86 28 8550357।

Fax +862885417273

Email blueljd@I63.com

\begin{abstract}
Nano-hydroxyapatite/polyamide 66 (nHA/PA66) composite with good bioactivity and osteoconductivity was employed to develop a novel porous membrane with asymmetric structure for guided bone regeneration (GBR). In order to test material cytotoxicity and to investigate surface-dependent responses of bone-forming cells, the morphology, proliferation, and cell cycle of bone marrow stromal cells (BMSCs) of rats cultured on the prepared membrane were determined. The polygonal and fusiform shape of BMSCs was observed by scanning electronic microscopy (SEM). The proliferation of BMSCs cultured on nHA/PA66 membrane tested by the MTT method (MTT: [3-\{4,5-dimethylthiazol-2yl\}-2,5-diphenyl-2H-tetrazoliumbromide]) was higher than that of negative control groups for 1 and 4 days' incubation and had no significant difference for 7 and 11 days' culture. The results of cell cycle also suggested that the membrane has no negative influence on cell division. The nHA/PA66 membranes were then implanted into subcutaneous sites of nine Sprague Dawley rats. The wounds and implant sites were free from suppuration and necrosis in all periods. All nHA/PA66 membranes were surrounded by a fibrous capsule with decreasing thickness 1 to 8 weeks postoperatively. In conclusion, the results of the in vitro and in vivo studies reveal that nHA/PA66 membrane has excellent biocompatibility and indicate its use in guided tissue regeneration (GTR) or GBR.
\end{abstract}

Keywords: hydroxyapatite/polyamide, barrier membrane, biocompatibility, guided bone regeneration

\section{Introduction}

Guided tissue regeneration (GTR) using barrier membranes has been proven as an effective modality in periodontal therapy. ${ }^{1}$ The barrier membrane technique was employed to guide bone regeneration in the bone defect site and given the name of "guided bone regeneration (GBR)" by some researchers. ${ }^{2}$ Criteria for ideal barrier membranes include biocompatibility, cell occlusiveness, space making, tissue integration and clinical manageability. In the past twenty years, nonabsorbable ${ }^{3-6}$ and absorbable membranes ${ }^{7-11}$ had been studied and applied to GTR or GBR techniques. However, both the absorbable and nonabsorbable barrier membranes have their shortcomings and the available products are limited. ${ }^{12-14}$

The main disadvantage for absorbable membranes is unexpected absorption ahead of sufficient bone forming, ${ }^{6}$ while the main disadvantage for nonabsorbable membranes is the need for a second surgery. ${ }^{15}$

The nano-hydroxyapatite/polyamide 66 (nHA/PA66) composite developed by our research group is a biomimetic and bioactive material for bone repair engineering. ${ }^{16}$ The nHA/PA66 composite dramatically resembles natural bone in its composition, 
structure, and mechanical properties, which is responsible for its good biocompatibility, osteoconductivity, and bioactivity. ${ }^{17-19}$ Our previous study revealed that the incorporation of nano-hydroxyapatite (nHA) in a polyamide 66 (PA66) matrix could improve properties of the membrane substantially. The elongation at break and the tensile strength suggest that the composite membrane (with $40 \mathrm{wt} \%$ of nHA) has good strength and toughness. ${ }^{20}$

In order to overcome the drawbacks of the currently-used barrier membranes and to provide an optimal alternative, our hypothesis is to develop a novel nHA/PA66 membrane which is nonabsorbable in nature and does not require retrieval.

This study assesses the in vitro cytotoxicity and in vivo biocompatibility of the novel membrane. The morphology, proliferation, and cell cycle of bone marrow stromal cells (BMSCs) of rats cultured on the prepared membrane were determined to test the material's cytotoxicity. In vivo biocompatibility was investigated in healthy SpragueDawley rats.

\section{Materials and methods Materials}

PA66 with a viscosity-average molecular weight (Mv) of $18 \mathrm{kDa}$ was obtained from BASF, (Ludwigshafen, Germany). The slurry of nano-hydroxyapatite used for the composite was prepared by our laboratory using the methods of wet synthesis and hydrothermal treatment..$^{21,22}$

\section{Fabrication of the nHA/PA66 membrane}

The nHA/PA66 (4:6 in wt\%) composite slurry was prepared according to previous work. ${ }^{19}$ PA66 was completely dissolved in ethanol solution at $70^{\circ} \mathrm{C}$. The nHA slurry was gradually added to the PA66/ethanol solution with vigorous stirring for $2 \mathrm{~h}$. The composite slurry was left standing for at least $4 \mathrm{~h}$ at room temperature to remove the bubbles. The slurry was poured onto a glass plate to form an even liquid film, which was then evaporated at room temperature for $24 \mathrm{~h}$ to form a membrane, and washed repeatedly with deionized water.

\section{Membrane characterization}

The microstructure of the nHA/PA66 membrane was observed under scanning electron microscope (SEM). The membranes were carefully sectioned with a razor blade and mounted onto copper stubs. Prior to examination, each sample was coated with gold. A Hitachi S-450 SEM microscope at $20 \mathrm{kV}$ was used to perform image analysis.

\section{Cell culture}

BMSCs were obtained from the tibiae and femora of young Sprague-Dawley rats and cultured in $\alpha$-MEM culture medium supplemented with $20 \%$ fetal FBS, $100 \mathrm{U} / \mathrm{mL}$ penicillin, $100 \mathrm{mg} / \mathrm{mL}$ streptomycin, $0.219 \mathrm{mg} / \mathrm{mL}$ L-glutamine, $100 \mathrm{mM}$ HEPES buffer (Gibco, USA) in a humidified incubator with $5 \% \mathrm{CO} 2$ at $37^{\circ} \mathrm{C}$. The culture media was changed every other day. The fourth passage BMSCs were used in the experiments.

\section{Cell seeding}

The nHA/PA66 membrane was prepared in a square form $(2 \mathrm{~cm} \times 3 \mathrm{~cm})$, sterilized by autoclaving, placed into 6 -well culture plate, and seeded at a density of $3 \times 106$ cells/well in $2 \mathrm{~mL}$ supplemented medium. The cell $/$ membrane constructs were cultured in a humidified incubator at $37^{\circ} \mathrm{C}$ with $5 \% \mathrm{CO} 2$ for 7 days. The medium was changed every other day. Cells cultured without membranes were assigned as control.

\section{Cellular morphology}

An inverted phase contrast microscope and a scanning electron microscope were used to determine cellular morphology.

BMSCs cultured on nHA/PA66 membrane were rinsed with phosphate buffered saline (PBS), fixed with $1 \%$ paraformaldehyde, subjected to graded alcohol dehydrations, rinsed with PBS, sputter-coated with gold, and examined with a scanning electron microscope (JSM-5900LV, Hitachi). The growth of cells on the scaffolds was observed by SEM at $24 \mathrm{~h}$ and $96 \mathrm{~h}$.

\section{Analysis of proliferation of the BMSCs}

The proliferation of BMSCs cells cultured on the nHA/PA66 membrane was determined by the MTT assay using an HTS 7000 plus Bio Assay Reader (Perkin Elmer, USA). The medium was removed and $2 \mathrm{~mL}$ of MTT solution $(5 \mathrm{mg} / \mathrm{mL})$ was added to each well. Following incubation at $37^{\circ} \mathrm{C}$ for $4 \mathrm{~h}$ in a fully-humidified atmosphere at 5\% CO2 in air, MTT was taken up by active cells and reduced in the mitochondria to insoluble purple formazan granules. Subsequently, the medium was discarded and the precipitated formazan was dissolved in dimethyl sulfoxide (DMSO) (150 mL/well). The optical density of the solution was evaluated using a microplate spectrophotometer at a wavelength of $490 \mathrm{~nm}$.

\section{Analysis of cell cycle}

At 1, 4, 7 days, cultures were trypsinized and centrifuged at $1000 \mathrm{rpm}$ for $8 \mathrm{~min}$, then resuspended in $1 \mathrm{~mL}$ of $70 \%$ ethanol. 
Cell cycle was determined using a flow cytometer $\left(\right.$ EPLCS $^{\circledR}$ ELITE, Coulter, USA).

\section{In vivo biocompatibility - subcutaneous implant test}

Nine Sprague-Dawley rats were anesthetized by an introabdominal injection of pentobarbital (Nembutal $3.5 \mathrm{mg} / 100 \mathrm{~g} \mathrm{BW}$ ) to undergo bilaterally dorsal subcutaneous implantation. Four subcutaneous pouches were created in the back of one rat, where membranes were implanted. After blunt dissection through the subcutaneous tissues, each rat received four pieces of membrane in the back. Skin incision was closed by simple interrupted sutures of monofilament nylon 4-0. The rats were randomly assigned into three groups with three in each group representing three different time points. The composites and surrounding tissue were obtained and processed for histological analysis at 1, 4, and 8 weeks after implantation. All samples were fixed in $10 \%$ buffered formalin, decalcified (K-CX solution, Falma Co., Tokyo, Japan), dehydrated, embedded in paraffin, and stained with hematoxylin and eosin. These samples were observed by optical microscope (Olympus, IX 70, Japan).

\section{Statistical analysis}

Statistical analysis was performed with SPSS 11.5. For all experiments, the results are expressed as mean \pm standard deviation, ' $n$ ' value was 5 , and independent experiments were performed three times. Analysis of variance (ANOVA) was performed, followed by Student-Newman-Keuls multiple comparison test. When a difference between groups was identified by ANOVA, a comparison of group means was performed using a Student's t-test. The value of $P<0.05$ was considered statistically significant.

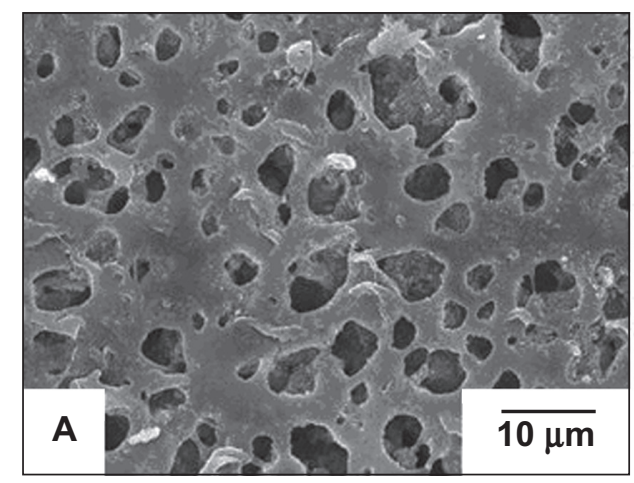

\section{Results and discussion}

The microstructure of the membrane

Figure 1 shows that the membrane has an asymmetric porous structure, in which pores less than $10 \mu \mathrm{m}$ are distributed on one side \{microporous layer (Figure 1A)\}, while pores ranging from $30 \mu \mathrm{m}$ to $200 \mu \mathrm{m}$ are located on the other side $\{$ macroporous layer (Figure 1B) $\}$. The microporous layer of the membrane can prevent the fibrous connective tissue from migrating into the bony defect, while being able to permeate sufficient nutrients for the regenerated tissue. Meanwhile the spongy structure of the membrane can promote ingrowth of progenitor bone cells, leading to direct bonding between the original and regenerated tissue. ${ }^{23}$ This particular layout features in the commercially available collagen bilayer membranes Bio-Gide ${ }^{\circledR}$. Its dense and smooth outer surface is covered by a particularly dense film, aiming at preventing the invasion of undesirable gingival epithelium and connective tissue cells into the membraneprotected area. The inner rough side of Bio-Gide ${ }^{\circledR}$ promotes the ingrowth of periodontal ligament (PDL) cells, bone cells, and cementoblasts. ${ }^{24}$

\section{The growth of cells on the surface of porous $\mathrm{nHA} / \mathrm{PA} 66$}

The morphology of BMSCs anchored on nHA/PA66 as observed by SEM is shown in Figure 2. The polygonal and fusiform BMSCs were well distributed over the membranes at various incubation periods. Cells cultured on the membrane for $96 \mathrm{~h}$ had dramatically reproduced and aggregated with each other to form cell layers. More filamentous fibers were formed on the surface of the cells, and cells penetrated into the pores of the membrane. This shows that the nHA/ PA66 membrane is favorable for BMSCs attachment and spreading.

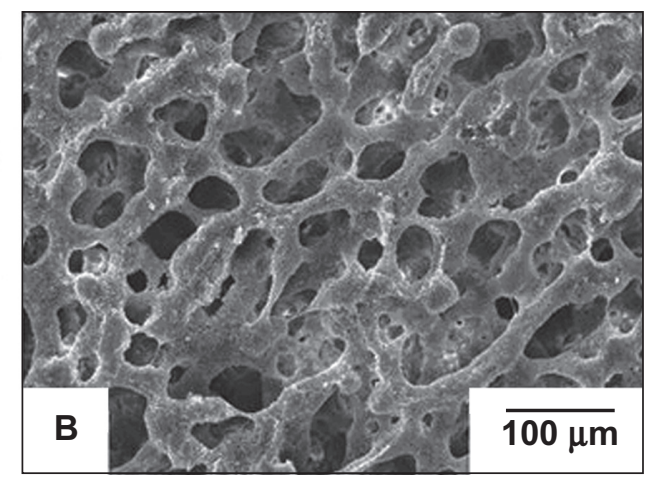

Figure I SEM photos of nHA/PA66 membrane: micropore surface (A) and spongy surface (B). 

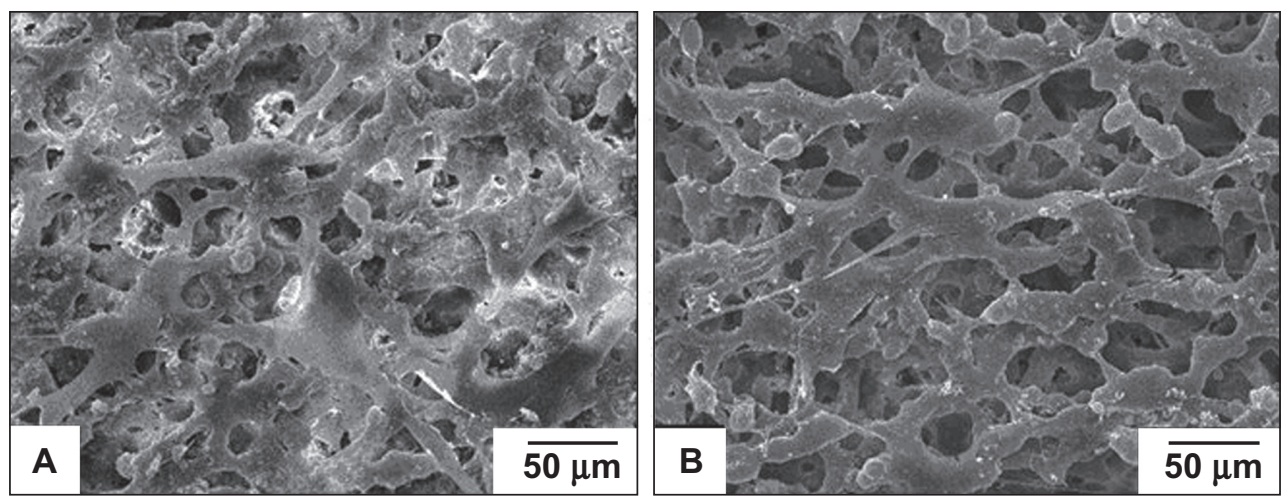

Figure 2 SEM micrographs of the BMSCs cultured on the nHA/PA66 membranes for $24 \mathrm{~h}(\mathbf{A})$ and $96 \mathrm{~h}$ (B), respectively.

\section{Observation under the inverted phase contrast microscope}

Figure 3 shows representative phase-contrast micrographs of BMSCs cultured with or without the membrane, at day 4 and day 7. Comparing Figure 3A with Figure 3B, or Figure 3C with Figure 3D, cells beside the membrane exhibited the same morphologic characteristics - polygonal and spindlelike shapes - as in the control group. Cellular densities in both groups were similar at the same indicated period, with a marked increase of cell population at day 7. It shows that the nHA/PA66 membrane has no deleterious or cytotoxic effect on the morphology and proliferation of BMSCs.
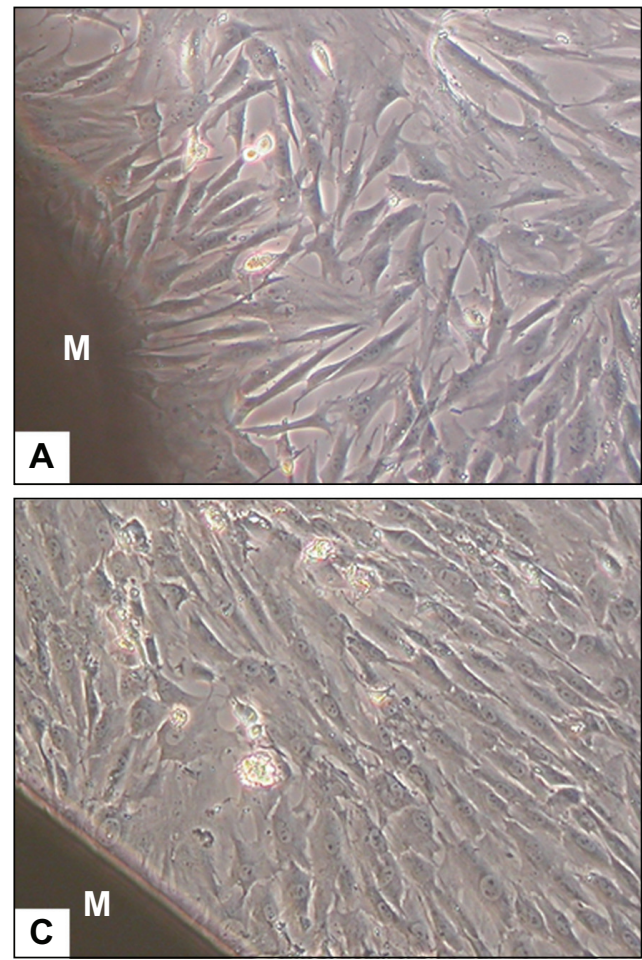

\section{Effect of nHA/PA66 membranes on viability of the BMSCs}

The proliferation of BMSCs cultured on the nHA/PA66 membrane was evaluated by MTT test (Figure 4). The cell number increased with the culture time on both the tested group and control group. The proliferation of BMSCs cultured on the nHA/PA66 membrane was higher than that of the negative control group for 1 and 4 days' incubation $(P<0.05)$. There was no significant difference of cell number between the two groups for 7 and 11 days' culture $(P>0.05)$ (Figure 4). This ascendant tendency of cell population demonstrates that nHA/PA66 membrane imposes little
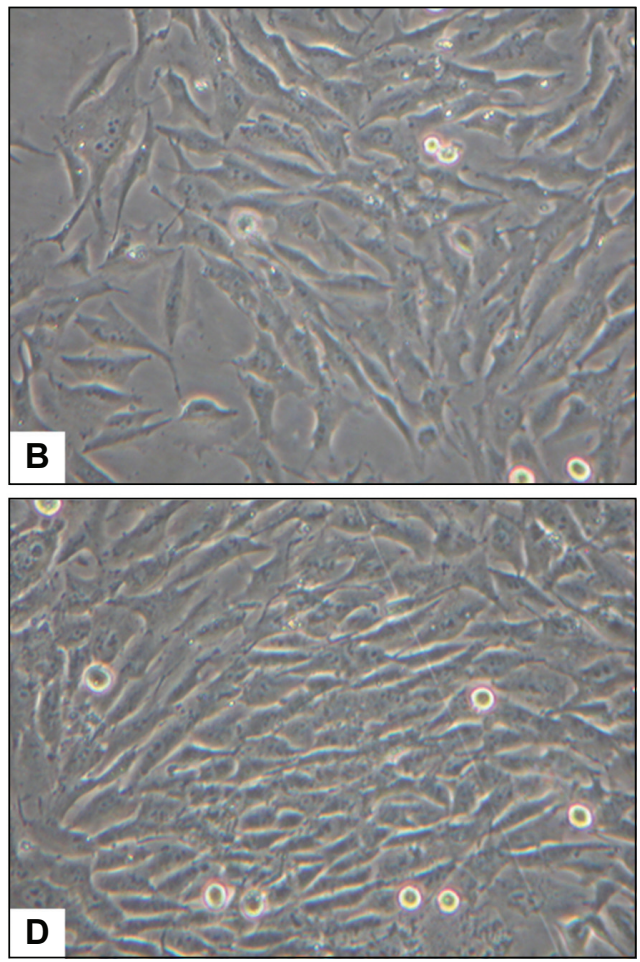

Figure 3 The cellular morphology and proliferation of BMSCs cultured with nHA/PA66 membrane and BMSCs (control) under inverted phase contrast microscope (magnification:200x) at day 4 (A, B) and day 7 (C, D). M stands for nHA/PA66 membrane. 


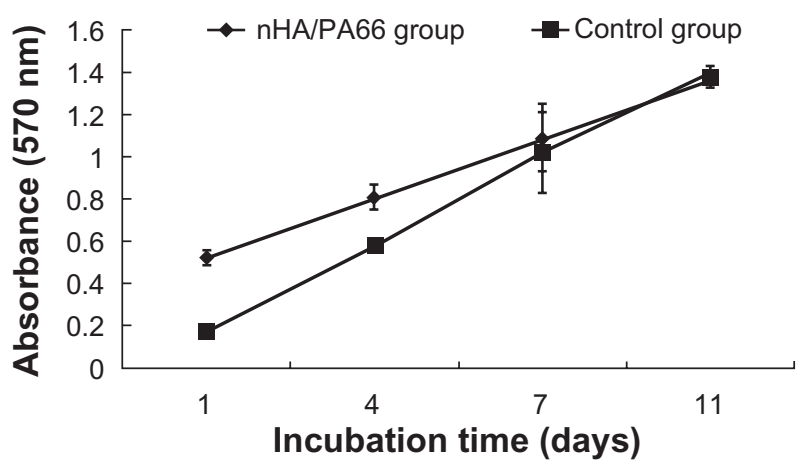

Figure 4 The proliferation of BMSCs (control) and BMSCs cultured with nHA/PA66 membrane at various incubation periods.

influence on BMSCs proliferation. PA66 is a polar compound containing $-\mathrm{COOH},-\mathrm{NH}_{2}$ and $-\mathrm{NH}-\mathrm{C}(\mathrm{O})$ - groups, which can promote adsorption of proteins such as fibronectin from the medium to enhance the cells' attachment. ${ }^{25}$ The addition of nHA in the polymer matrix can also increase adsorption of proteins ${ }^{26}$ to facilitate cell attachment, spreading, and proliferation. The good hydrophilicity may be another reason for the excellent cell affinity of nHA/PA66 membrane. ${ }^{20}$

\section{Analysis of cell cycle}

The distribution of different phases of BMSCs cultured with or without nHA/PA66 membrane is reported in Table 1. The cell cycle of BMSCs cultured with nHA/PA66 was not affected in comparison with the control group. Although most cells were blocked in the G0G1 phase due to contact inhibitation resulting from high cell density for 4 and 7 days' incubation in both groups, cells in the $\mathrm{S}$ and G2M phases of the test group were higher than in the control group. The results suggest that the proliferation of BMSCs cultured on nHA/PA66 porous membrane is promoted. The results of in vitro experiments indicate that $\mathrm{nHA} / \mathrm{PA} 66$ membrane has good cell affinity and excellent biocompatibility.

\section{Biocompatibility in vivo}

A subcutaneous implantation test is an important step to explore host response to foreign materials. Three time points were selected to investigate the tissue reaction at acute

Table I Distribution in the different phases of BMSCs (control) and BMSCs cultured with nHA/PA66 membrane

\begin{tabular}{|c|c|c|c|c|c|c|c|c|c|}
\hline \multirow[t]{2}{*}{ Sample } & \multicolumn{3}{|c|}{ G0G I } & \multicolumn{3}{|l|}{$\mathbf{S}$} & \multicolumn{3}{|c|}{ G2M } \\
\hline & I d & $4 d$ & $7 d$ & I d & $4 d$ & $7 \mathrm{~d}$ & I d & $4 d$ & $7 d$ \\
\hline nHA/PA66 & 11.8 & 74.8 & 72.7 & 67.1 & 14.4 & 15.3 & 21.1 & 10.7 & 12.0 \\
\hline Control & 12.4 & 77.9 & 81.8 & 50.2 & 13.6 & 11.4 & 37.4 & 8.5 & 6.8 \\
\hline
\end{tabular}

Abbreviations: BMSCs, bone marrow stromal cells; nHA/PA66, nanohydroxyapatite/polyamide 66 . (one week), transitional (four weeks), and chronic phases (eight weeks) respectively. The wounds and implantation sites were free from suppuration and necrosis after subcutaneous implantation in all periods. Histological study revealed a fibrous capsid with inflammatory cellular infiltration around the membrane at 1 week (Figure 5A). It indicated that the implant induced a mild acute inflammation, which was characterized by the infiltration of inflammatory cells - mainly polymorphonuclear cells and lymphocytes - at the interface between the implant and tissue (Figure 5B). Observation at 4 weeks showed a reduced inflammatory infiltrate. Sparse neovascularization could be observed within the porous structure of the membrane. The capsule became better organized. At 8 weeks, the fibrous encapsulation was well-defined, thinner and more mature with pronounced vascularization around the membrane (Figure 5C). No severe inflammation, hemorrhage or necrosis was induced around the implants. Over the time, the surrounding connective tissues displayed a reduced inflammation process and the membrane was present at all evaluation points with no signs of resorption. Foreign body reaction, which is indicated by multinucleated giant cells, was not observed throughout the study period. Absence of a foreign body reaction negates the necessity of additional surgery for removal of the device. ${ }^{27}$

In our previous study, nano-hydroxyapatite/polyamide (nHA/PA) composite scaffolds were implanted in rabbit mandibles. At 8 weeks post-implantation, the boundary between material and host bone became unclear due to the sufficient formation of mature bone tissues which had ingrown into the pores of the artificial scaffold and bonded tightly with the material. With the implantation period prolonged, new bone regenerated and penetrated through the interconnective pores to the center of the scaffolds, increasing the quantity and density of the defective area. At 12 weeks, the interface between material and host bone was hardly detectable and formed a close union without any gap. ${ }^{17}$ The previous study confirmed the extensive osteoconductivity and bone regeneration potential of the nano-hydroxyapatite/ polyamide (nHA/PA) composite scaffolds.

As a novel membrane designed for GBR, the effect of nHA/PA66 membrane will be further investigated in our subsequent GBR experimental study. Within the limitation of the present study, the results indicate that the nHA/PA66 composite has desirable in vivo biocompatibility. Since the body didn't exclude the membrane and the composite incorporated with surrounding tissue harmoniously, it is possible to maintain the membrane in situ without retrieval. 

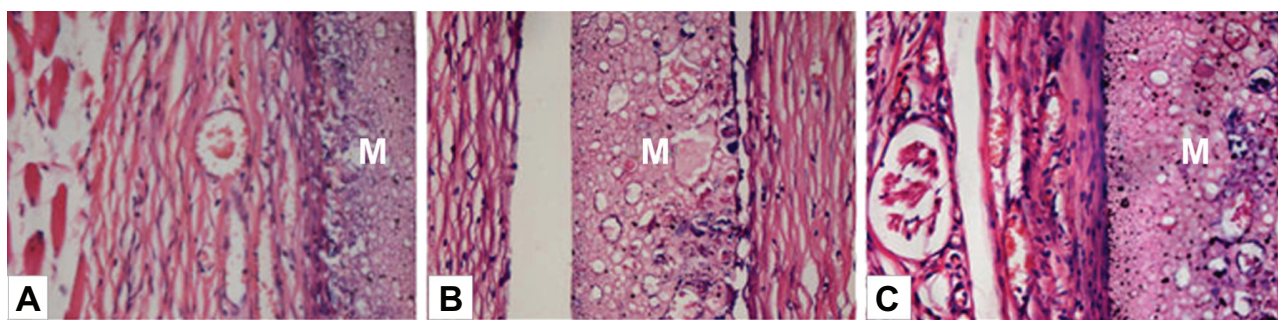

Figure 5 Hematoxylin/eosin-stained sections of subcutaneously-implanted nHA/PA66 membrane and surrounding tissue, which were harvested at I (A), 4 (B), and 8 (C) weeks post-implantation (magnification:400x). In the photos, M denotes the nHA/PA66 membrane.

\section{Conclusions}

The interest in developing an ideal barrier membrane for GTR or GBR drives us to focus on preparing the novel nano-hydroxyapatite/polyamide 66 membrane. The results demonstrate that the n-HA/PA66 membrane is a gradient porous 3-D structure with a microporous dense layer on one side and a macroporous spongy layer on the other side. In vitro experiments show that nHA/PA66 membrane has good affinity for BMSCs attachment, and no negative effects on cell viability and proliferation. Subsequently, a subcutaneous implantation test was employed for in vivo evaluation of the bio-compatibility of the membrane. Macroscopic and histological observation revealed no foreign body reaction and a reduced inflammation process. The good biocompatibility of the membrane can meet the requirement of GBR. The nHA/PA66 membrane has the potential to be employed as a novel barrier membrane.

\section{Acknowledgments and disclosures}

This work was supported by China 973 fund (No. 2007CB936102) and a grant from the State Key Laboratory of Oral Diseases (free application Project No. SKLODP007). The authors report no conflicts of interest in this work.

\section{References}

1. Kostopoulos L, Karring T. Augmentation of the rat mandible using guided tissue regeneration. Clin Oral Implants Res. 1994;5:75-82.

2. Dahlin C, Sennerby L, Lekholm U, Linde A, Nyman S. Generation of new bone around titanium implants using a membrane technique: an experimental study in rabbits. Int J Oral Maxillofac Implants. 1989;4:19-25.

3. Zitzmann NU, Naef R, Scharer P. Resorbable versus nonresorbable membranes in combination with Bio-Oss for guided bone regeneration. Int J Oral Maxillofac Implants. 1997;12:844-852.

4. Schenk RK, Buser D, Hardwick WR, Dahlin C. Healing pattern of bone regeneration in membrane-protected defects: a histologic study in the canine mandible. Int J Oral Maxillofac Implants. 1994;9:13-29.

5. Wang DM, Lin FC, Chen LY, Lai JY. Application of asymmetric TPX membranes to transdermal delivery of nitroglycerin. J Control Release. 1998;50:187-195.

6. Nasser NJ, Friedman A, Friedman M, Moor E, Mosheiff R. Guided bone regeneration in the treatment of segmental diaphyseal defects: a comparison between resorbable and non-resorbable membranes. Injury. 2005;36:1460-1466.
7. Zhang YZ, Su B, Venugopal J, Ramakrishna S, Lim CT. Biomimetic and bioactive nanofibrous scaffolds from electrospun composite nanofibers. Int J Nanomedicine. 2007;2:623-638.

8. Hong H, Wei J, Liu CS. Development of asymmetric gradationalchanged porous chitosan membrane for guided periodontal tissue regeneration. Compos Part B Eng. 2007;38:311-316.

9. Owen GR, Jackson J, Chehroudi B, Burt H, Brunette DM. A PLGA membrane controlling cell behaviour for promoting tissue regeneration. Biomaterials. 2005;26:7447-7456.

10. Hammerle CH, Lang NP. Single stage surgery combining transmucosal implant placement with guided bone regeneration and bioresorbable materials. Clin Oral Implants Res. 2001;12:9-18.

11. Kim KH, Jeong L, Park HN, et al. Biological efficacy of silk fibroin nanofiber membranes for guided bone regeneration. $J$ Biotechnol. 2005;120:327-339.

12. Lundgren AK, Sennerby L, Lundgren D. Guided jaw-bone regeneration using an experimental rabbit model. Int J Oral Max Surg. 1998;27:135-140.

13. Nowzari H, Slots J. Microbiologic and clinical study of polytetrafluoroethylene membranes for guided bone regeneration around implants. Int J Oral Maxillofac Implants. 1995;10:67-73.

14. Machtei EE. The effect of membrane exposure on the outcome of regenerative procedures in humans: a meta-analysis. $J$ Periodontol. 2001;72:512-516.

15. Nociti FH Jr, Machado MA, Stefani CM, Sallum EA, Sallum AW. Absorbable versus nonabsorbable membranes and bone grafts in the treatment of ligature-induced peri-implantitis defects in dogs. Part I. A clinical investigation. Clin Oral Implants Res. 2001;12:115-120.

16. Wang X, Li Y, Wei J, de Groot K. Development of biomimetic nano-hydroxyapatite/poly(hexamethylene adipamide) composites. Biomaterials. 2002;23:4787-4791.

17. Wang H, Li Y, Zuo Y, Li J, Ma S, Cheng L. Biocompatibility and osteogenesis of biomimetic nano-hydroxyapatite/polyamide composite scaffolds for bone tissue engineering. Biomaterials. 2007;28:3338-3348.

18. Zhang L, Li YB, Wang XJ, Wei J, Peng XL. Studies on the porous scaffold made of the nano-HA/PA66 composite. J Mater Sci. 2005;40:107-110.

19. Zhang X, Li YB, Zuo Y, Lv GY, Mu YH, Li H. Morphology, hydrogenbonding and crystallinity of nano-hydroxyapatite/polyamide 66 biocomposites. Compos Part A Appl Sci Manuf. 2007;38:843-848.

20. Li JD, Zuo Y, Cheng XM, Yang WH, Wang HN, Li YB. Preparation and characterization of nano-hydroxyapatite/polyamide 66 composite GBR membrane with asymmetric porous structure. J Mater Sci Mater Med. 2009;20:1031-1038.

21. Li YB, de Wijn J, Klein CPAT, van de Meer S, de Groot K. Preparation and characterization of nanograde osteoapatite-like rod crystals. J Mater Sci Mater Med. 1994;5:252-255.

22. Smith IO, McCabe LR, Baumann MJ. MC3T3-E1 osteoblast attachment and proliferation on porous hydroxyapatite scaffolds fabricated with nanophase powder. Int J Nanomedicine. 2006;1:189-194.

23. Cerroni L, Filocamo R, Fabbri M, Piconi C, Caropreso S, Condo SG. Growth of osteoblast-like cells on porous hydroxyapatite ceramics: an in vitro study. Biomol Eng. 2002;19:119-124. 
24. Hillmann G, Steinkamp-Zucht A, Geurtsen W, Gross G, Hoffmann A. Culture of primary human gingival fibroblasts on biodegradable membranes. Biomaterials. 2002;23:1461-1469.

25. Hynes RO. Integrins: versatility, modulation, and signaling in cell adhesion. Cell. 1992;69:11-25.

26. Wei G, Ma PX. Structure and properties of nano-hydroxyapatite/polymer composite scaffolds for bone tissue engineering. Biomaterials. 2004;25:4749-4757.
27. Linde A, Alberius P, Dahlin C, Bjurstam K, Sundin Y. Osteopromotion: a soft-tissue exclusion principle using a membrane for bone healing and bone neogenesis. J Periodontol. 1993;64 Suppl 11:1116-1128.

International Journal of Nanomedicine

\section{Publish your work in this journal}

The International Journal of Nanomedicine is an international, peerreviewed journal focusing on the application of nanotechnology in diagnostics, therapeutics, and drug delivery systems throughout the biomedical field. This journal is indexed on PubMed Central, MedLine, CAS, SciSearch $\AA$, Current Contents ${ } /$ Clinical Medicine,
Journal Citation Reports/Science Edition, EMBase, Scopus and the Elsevier Bibliographic databases. The manuscript management system is completely online and includes a very quick and fair peer-review system, which is all easy to use. Visit http://www.dovepress.com/ testimonials.php to read real quotes from published authors.

Submit your manuscript here: http://www.dovepress.com/international-journal-of-nanomedicine-journal 